\title{
IGLESIA DE LOS SAGRADOS CORAZONES DE MADRID. ARQUITECTURA Y ARTE Silvia Blanco Agüeira
}

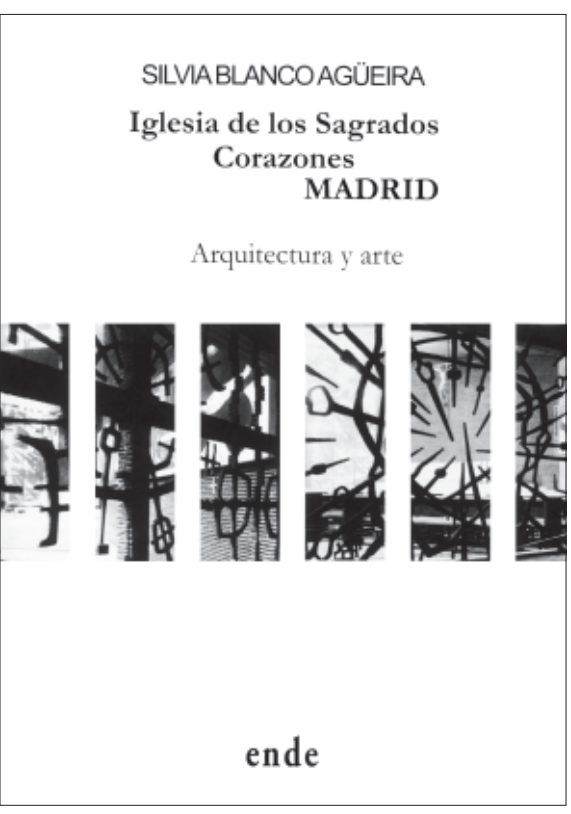

A Coruña: Ende, 2014

144 págs.; ilustraciones en blanco y negro; $21 \mathrm{~cm}$. ISBN: 978-84-942618-7-9

Boletín Académico. Revista de investigación y arquitectura contemporánea Escuela Técnica Superior de Arquitectura. Universidade da Coruña elSSN 2173-6723

uww.boletinacademico.com

Número 5 (2015)

Páginas 77-78

Fecha de recepción: 27.10 .2014

Fecha de aceptación: 04.11.2014

https:/doi.org/10.17979/bac.2015.5.0.1042

La iglesia de los Sagrados Corazones es, para muchos, la parroquia situada al lado del estadio Santiago Bernabeu. Sin embargo, este templo proyectado por Rodolfo García-Pablos y González-Quijano entre 1961 y 1965 condensa en su arquitectura los logros de una época especialmente significativa para la arquitectura moderna espańola y para la evolución del espacio de culto. Unos logros que, gracias al último trabajo de Silvia Blanco Agüeira podremos conocer y revisar, descubriéndonos nuevas e interesantes miradas sobre su historia.

A través de un discurso preciso y altamente didáctico — dos de las grandes virtudes extensibles a toda la producción científica de la autora - se nos presenta el análisis de una iglesia singular que —al igual que su arquitecto- nunca se posicionó como protagonista de la modernidad. Sin embargo, este «actor secundario» —empleando las palabras que figuran en el texto-, resolvió el encargo con oficio y profesionalidad, legándonos una obra que, analizada desde la perspectiva actual, constituye un referente fundamental para entender, tanto el avance de la arquitectura religiosa en España como los fecundos caminos que paralelamente recorrió la modernidad.

El libro nos ofrece un exhaustivo análisis sobre el proyecto de la iglesia, partiendo de las intenciones iniciales y los referentes internacionales que manejó García-Pablos, hasta llegar a la solución materializada, dedicando una atención especial a la integración de las artes, una valiosa aportación de la arquitectura del momento y que en esta obra alcanza notables cotas de calidad, tanto por el valor de las intervenciones como por los artistas implicados.

En relación con este tema, hay que destacar el interés por buscar el testimonio directo de todos los participantes: José Luis Sánchez, Joaquín Vaquero Turcios, Carlos Muñoz de Pablos, Francisco Farreras y José Luis Alonso Coomonte, recogido a través de una serie de entrevistas realizadas por la autora incluidas como anexos y que nos sirven para conocer en detalle cómo fue la relación con la obra y con el arquitecto. 
El texto se completa con abundante información gráfica, planos y fotografías —en su mayoría procedentes del archivo profesional de García-Pablos-, y con un conjunto de documentos entre los que destacan los sugestivos dibujos a mano alzada que el arquitecto realizó para acompañar a la conferencia «Nueva liturgia. Nueva arquitectura» impartida en el interior de la iglesia en 1964.

Nos encontramos, por tanto, ante un libro que, a pesar de su reducido tamaño, nos ofrece un análisis de arquitectura amplio y riguroso y, al mismo tiempo, de lectura amena y agradable, que consigue trasladarnos a la atmósfera de uno de los templos más interesantes de la modernidad espańola, de la mano de una autora que, sobre este trabajo, podría subscribir perfectamente las palabras de García-Pablos recogidas en el texto: «No sé si esta obra podrá considerarse como buena. Si sé que he puesto todo mi corazón y mi experiencia para lograr una solución estimable».

Antonio S. Río Vázquez 